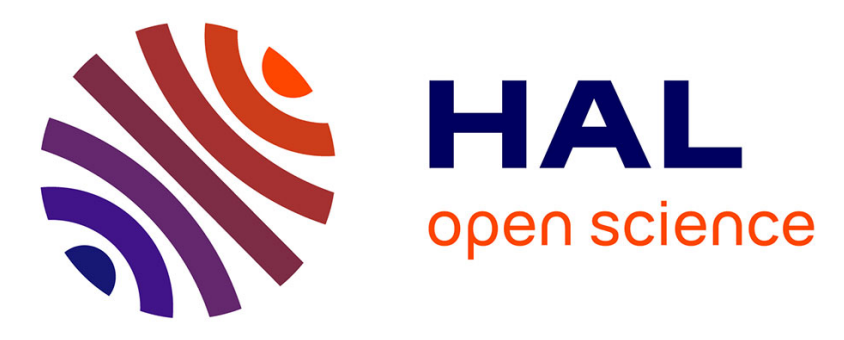

\title{
Viewing another person's body as a target object: a behavioural and PET study of pointing.
}

\author{
Laurent Cleret de Langavant, Iris Trinkler, Philippe Remy, Bérangère
}

Thirioux, Joseph Mcintyre, Alain Berthoz, Emmanuel Dupoux, Anne-Catherine Bachoud-Lévi

\section{To cite this version:}

Laurent Cleret de Langavant, Iris Trinkler, Philippe Remy, Bérangère Thirioux, Joseph Mcintyre, et al.. Viewing another person's body as a target object: a behavioural and PET study of pointing.: Pointing at a person's body. Neuropsychologia, 2012, 50 (8), pp.1801-13. 10.1016/j.neuropsychologia.2012.04.005 . inserm-00732068

\section{HAL Id: inserm-00732068 https://www.hal.inserm.fr/inserm-00732068}

Submitted on 13 Sep 2012

HAL is a multi-disciplinary open access archive for the deposit and dissemination of scientific research documents, whether they are published or not. The documents may come from teaching and research institutions in France or abroad, or from public or private research centers.
L'archive ouverte pluridisciplinaire HAL, est destinée au dépôt et à la diffusion de documents scientifiques de niveau recherche, publiés ou non, émanant des établissements d'enseignement et de recherche français ou étrangers, des laboratoires publics ou privés. 
Cleret de Langavant et al.

\section{Viewing another person's body as a target object: a behavioural and PET study of pointing}

Laurent Cleret de Langavant ${ }^{\mathrm{abcd}}$, Iris Trinkler ${ }^{\mathrm{abc}}$, Philippe Remy ${ }^{\text {cde }}$, Bérangère Thirioux ${ }^{\mathrm{f}}$, Joseph McIntyre $^{\mathrm{g}}$, Alain Berthoz ${ }^{\mathrm{f}}$, Emmanuel Dupoux ${ }^{\mathrm{bh}}$, Anne-Catherine Bachoud-Lévi ${ }^{\text {abcd }}$

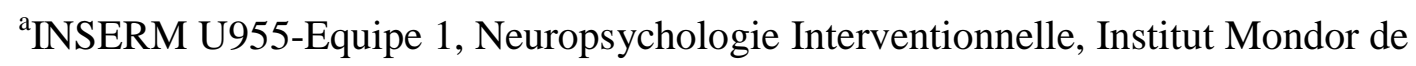

Recherche Biomédicale, Créteil, France

${ }^{\mathrm{b}}$ Ecole Normale Supérieure, Département d'Etudes Cognitives, Paris, France

${ }^{c}$ AP-HP, Service de Neurologie, Groupe Hospitalier Universitaire Mondor Chenevier,

Créteil, France

${ }^{\mathrm{d}}$ Université Paris Est, Faculté de Médecine, Créteil, France

${ }^{\mathrm{e} U R A}$ LMN-CNRS-CEA 2210, SHFJ \& MIRcen, Orsay, France

${ }^{\mathrm{f}}$ LPPA, Collège de France, Paris, France

${ }^{\mathrm{g}}$ CESeM UMR 8194, Institut des Neurosciences et de la Cognition, Université Paris Descartes and CNRS, Paris, France

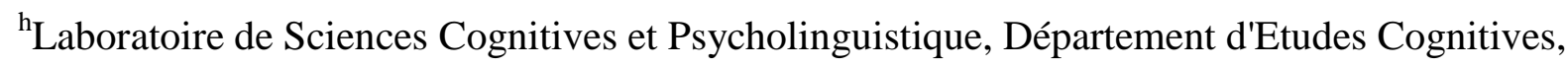
ENS-EHESS-CNRS, Paris, France

\section{Corresponding author:}

Address: Service de Neurologie, hôpital Henri Mondor, 51 av du maréchal de Lattre de Tassigny, 94010 CRETEIL, France

E-mail address:ㅁachoud@gmail.com

Tel +33149812315

Fax +33149812326

Shortened title: Pointing at a person's body 
Cleret de Langavant et al.

\section{Number of Figures: 5}

Number of Tables: 4

\section{Abbreviations}

BA: Brodmann area

$c R T$ : corrected reaction time

dur: duration (of the movement)

fMRI: functional magnetic resonance imaging

LpIPS: left posterior intraparietal sulcus

maxvel: maximal velocity

MNI: Montreal Neurological Institute

PET: positron-emission tomography

rCBF: regional cerebral blood flow

$R T$ : reaction time

SD: standard deviation

3D: three-dimensional

traj: length of the finger trajectory

$t t p$ : time to peak of maximal velocity

$t f p$ : time from peak of maximum velocity 
Cleret de Langavant et al.

\begin{abstract}
Humans usually point at objects to communicate with other persons, although they generally avoid pointing at the other's body. Moreover, patients with heterotopagnosia after left parietal damage cannot point at another person's body parts, although they can point at objects and at their own body parts and although they can grasp the others' body parts. Strikingly, their performance gradually improves for figurative human body targets. Altogether, this suggests that the body of another real person holds a specific status in communicative pointing. Here, we test in healthy individuals whether performance for communicative pointing is influenced by the communicative capacity of the target. In Experiment 1, pointing at another real person's body parts was compared to pointing at objects, and in Experiment 2, the person was replaced by a manikin. While reaction times for pointing at objects were shorter compared to pointing at other person's body parts, they were similar for objects and manikin body parts. By adapting Experiment 1 to PET-scan imaging (Experiment 3), we showed that, compared to pointing at objects, the brain network for pointing at other person's body parts involves the left posterior intraparietal sulcus, lesion of which could cause heterotopagnosia. Taken together, our results indicate that the specificity of pointing at another person's body goes beyond the visuo-spatial features of the human body and might rather rely on its communicative capacity.
\end{abstract}


Cleret de Langavant et al.

\section{Research highlights}

Pointing at other's body is avoided in humans and impaired in heterotopagnosia.

The communicative ability of the other person's body might be critical in pointing.

Pointing at another person's body parts is slower than pointing at objects.

Pointing at a manikin's body parts is comparable to pointing at objects.

Left posterior parietal cortex processes the body of another person while pointing.

Key words: heterotopagnosia, social cognition, joint attention, psychophysics, positronemission tomography 
Cleret de Langavant et al.

\section{Introduction}

Although the gesture of pointing at objects is commonly achieved in daily life, pointing at somebody else is frequently avoided, as demonstrated, for example, by advice for tourists on web sites of social etiquette (e.g. in North America, Europe, Japan, Vietnam, Thailand, Malaysia, Africa...). Such an attitude could remain anecdotal if pointing was not one of the most specific and fundamental skills in human social cognition (Kita, 2002). Indeed, pointing allows humans to communicate with another subject about an object or an event starting from the end of the first year of life (Tomasello, Carpenter, Call, Behne, \& Moll, 2005). The absence or the delay in the acquisition of pointing in children precedes developmental deficits of social interaction, such as autism (Baron-Cohen, 1989, 1995; Charman, 2003).

In adults, lesions of the left posterior parietal cortex can induce a syndrome called heterotopagnosia that specifically hampers pointing at other people's body parts whereas pointing at one's own body parts and at objects remains flawless (Auclair, Noulhiane, Raibaut, \& Amarenco, 2009; Cleret de Langavant, Trinkler, Cesaro, \& Bachoud-Levi, 2009; Degos, Bachoud-Lévi, Ergis, Petrissans, \& Cesaro, 1997; Degos \& Bachoud-Lévi, 1998; Felician, Ceccaldi, Didic, Thinus-Blanc, \& Poncet, 2003). In heterotopagnosia, patients' pointing performance progressively improves for figurative representations of the human body ranging from pictures and videos to dolls and drawings (Cleret de Langavant, Trinkler, Cesaro, \& Bachoud-Levi, 2009, but see Felician, Ceccaldi, Didic, Thinus-Blanc, \& Poncet, 2003). Accordingly, a patient with heterotopagnosia performed better in the task of pointing at another person's body parts when instructed to consider the living human body facing him as a non-living and non-communicative doll. Finally, patients with heterotopagnosia can grasp or touch another person's body parts that they cannot point at, indicating that their deficit is linked to the communicative value of the pointing gesture (Cleret de Langavant, Trinkler, Cesaro, \& Bachoud-Levi, 2009). This suggests, first, that the deficit for pointing at 
Cleret de Langavant et al.

another's body parts depends of the communicative exchange, and second, that this peculiar deficit does not rely only on the visuo-spatial features of the human body as a target compared to objects but rather on the body's communicative capacity. Presumably, specific mechanisms developed for detecting potential addressees (i.e. bodies having a capacity for communication) might intervene in the communicative exchange of pointing. Thus, one might suspect that a patient's deficit in heterotopagnosia is explained by an interaction between the communicative function of the pointing task and the communicative capacity of the target.

Indeed, in the specific task of pointing at another person's body, the participants simultaneously deal with two views onto another person's body: an addressee to communicate with and an object to communicate about. Both components might be critical for observing patients' deficits in heterotopagnosia (Cleret de Langavant, Trinkler, Cesaro, \& BachoudLevi, 2009). Thus in a first study, we explored the influence of an addressee to communicate with during pointing (Cleret de Langavant et al., 2011). We applied the psychophysical measure of endpoint variability, classically used for demonstrating the building of reference frames (egocentric or allocentric) necessary for planning pointing movements. We analyzed the endpoint variability of pointing directed at the same targets (around 20 gestures) in two conditions: communicative pointing and non-communicative pointing. We showed that the pointing gesture directed at objects is spatially shaped according to the communicative relationship between the subject and the addressee: it adapts to the position of the addressee with respect to the pointing participant. This suggests that in order to communicate with an addressee through pointing, we build what we called a "heterocentric" reference frame onto the body and perspective of the addressee (Cleret de Langavant, Trinkler, Cesaro, \& Bachoud-Levi, 2009). This indicates that pointing for communicative purposes implies a different behaviour than pointing without communication (Cleret de Langavant, et al., 2011). In addition, communication with an addressee influenced reach-to-grasp kinematics, as 
Cleret de Langavant et al.

revealed by a modification of both hand trajectory and aperture (Sartori, Becchio, Bara, \& Castiello, 2009). However, the direct comparison used for the diagnosis of heterotopagnosia between communicative pointing at objects and communicative pointing at real human body parts remains to be explored at behavioural and neural levels in healthy participants.

In this paper we focus on the influence of the target upon pointing, with a psychophysical and PET study. More specifically we study the influence of another person's body, when it is viewed as the target object of communicative pointing. We tested pointing at body parts in healthy participants in two behavioural experiments by using a set-up similar to the one used in patients with heterotopagnosia, i.e. alternating instructions for pointing at themselves and for pointing at another person's body parts, and comparing performance for body parts and objects on the body (Cleret de Langavant, Trinkler, Cesaro, \& Bachoud-Levi, 2009; Degos, Bachoud-Lévi, Ergis, Petrissans, \& Cesaro, 1997; Felician, Ceccaldi, Didic, Thinus-Blanc, \& Poncet, 2003). In Experiment 1, participants were required to point at another person's body parts or at objects while interacting with addressees who named the pointed target after the gesture. We measured both the spatio-temporal parameters and the planning phase (with reaction times) of the gestures: the former are influenced by the spatial characteristics (size, shape, orientation) of the target (Castiello, 2005), the latter by a wider range of visual and cognitive information (Glover, 2004, but see Bennett, Thomas, Jervis, \& Castiello, 1998, for semantic category). However, the influence of the communicative ability of the human body target upon the pointing gesture is presumably more conceptual than perceptual (Cleret de Langavant, Trinkler, Cesaro, \& Bachoud-Levi, 2009), and it should impact the planning phase of the movement. In addition, because pointing at the other's body imposes to deal simultaneously with the views of the person's body as an addressee and as an object (Cleret de Langavant, Trinkler, Cesaro, \& Bachoud-Levi, 2009), pointing at the other's real body targets should be slower compared to pointing at objects. In order to disentangle whether such 
Cleret de Langavant et al.

a difference would rely on distinct visuo-spatial features of body parts and objects or on the communicative capacity of the human body, we set a control experiment in which we replace the human target by a manikin (Experiment 2). If the specificity of the human body relates to its visuo-spatial features, the experiment using a manikin should provide similar results to those of Experiment 1 with a real human target, thus showing slower pointing for body parts than for objects. In contrast, if the communicative capacity of the body activates a specific representation during pointing, the manikin should be considered as an object and thus should yield similar reaction times and movement parameters to those of objects. Finally, previous neuroimaging studies in healthy participants used figurative human body representations and non-communicative tasks, thus leading to the activation of body-related brains areas distinct from that/those impaired in heterotopagnosia. Here, in Experiment 3 we examined the neural correlates of communicative pointing using both target and task requirements: other person's body parts and objects as targets in a positron-emission tomography (PET) study of communicative pointing. We expected the comparison between pointing at another person's body versus pointing at an object to activate the same area located in the left posterior intraparietal sulcus lesionned in heterotopagnosia (Auclair, Noulhiane, Raibaut, \& Amarenco, 2009; Cleret de Langavant, Trinkler, Cesaro, \& Bachoud-Levi, 2009). We would then confirm that there are cognitive and neural processes, which are dedicated to the representation of the communicative body of other humans as targets of pointing. This should ground the inability to point at another person's body in heterotopagnosia on a specific behavioural and neural representation of the body of other people, rather than on an anecdotal taboo.

2. Experiment 1: Behavioural study of pointing at another person's body versus objects

\subsection{Methods}

\subsubsection{Participants}


Cleret de Langavant et al.

Twenty right-handed healthy volunteers (selected according to the Oldfield handedness inventory, Oldfield, 1971) were tested (10 women, 10 men; mean age $27.4 \pm 7.7$ years). Mean education level was 15.7 SD \pm 1.8 years after primary school, and none had a history of neurological disease or treatment. Local ethics-committee approval and the participants' written informed consent were obtained before the start of the study.

\subsubsection{Procedure and apparatus}

The experiment involved 4 persons: one who pointed at a target, designated as "the participant" and 3 others who could act alternatively as addressees or as targets. They were seated face to face 2 by 2 (Figure 1). The addressees wore T-shirts bearing the name they were given for the experiment (e.g. "Luc" or "Jeanne"). The target person facing the participant could be either a male or a female, in equal proportion. Ten similar objects were placed on the body parts of each of the four persons. In order to avoid bias for location, objects were located on target body parts. Body parts were as follows: forehead, nose, right ear left ear, neck, left wrist, right knee, left knee, right foot and left foot (in French, front, nez, oreille droite, oreille gauche, cou, poignet gauche, genou droit, genou gauche, pied droit, pied gauche); objects located on the body were cap, glasses, right earring, left earring, scarf, watch, right knee pad, left knee pad, right shoe and left shoe (in French, casquette, lunettes, boucle d'oreille droite, boucle d'oreille gauche, écharpe, montre, genouillère droite, genouillère gauche, chaussure droite, chaussure gauche). The lexical frequencies of both body parts and object names were similar according to a French data base (Lexique 3, New et al., 2007; $\mathrm{t}=1.34, \mathrm{p}>0.05)$.

The participant held down an answer button with the right index finger. He/she wore headphones to hear instructions for pointing at either a body part or at an object while communicating with one of the addressees. Body parts and objects targets were not mixed but randomly displayed in 10 alternating blocks of 10 trials each. The order of presentation of the 
Cleret de Langavant et al.

two types of blocks was counterbalanced across participants (objects first or body parts first). Before each block, the participant was informed via the headphones whether he or she would be asked to point at objects or at body parts. Then in turn, he/she provided aloud such information to the addresses so they would know what he/she would point to despite their similar location of objects and body parts. In addition, each trial was preceded by an instruction which indicated first to whom the pointing gesture should be addressed (see Figure 1 for details) and then the name of the target. As soon as he heard the name of the addressee, the participant called the addressees name aloud, such that the addressee knew that he/she would have to name the pointed target. The participant then pointed to the target (thus releasing the button), the addressee announced out loud the target of the pointing gesture, and the participant acknowledged the correctness of the response. Having several addressees and conditions created an effective and durable communicative interaction. After each trial, the participant pushed down the answer button again to hear the next instruction. The button was held down until the beginning of the next pointing gesture.

Forty gestures were directed at the participant, 40 at the target person facing the participant; 10 to the left flanking person and 10 the right flanking person. This yielded a total of 100 pointing gestures by each participant, plus an additional 5 training trials. For each target person, half the targets were body parts and half objects. A person could not be both the addressee and the target at the same time. Thus, when the target was the facing person, the right or the left flanking person were designated as the addressee, whereas when the target was one of the flanking persons, then the facing person was the addressee. Gestures directed to the facing-person's body and at the self were the main focus of interest in this study; other gestures were used to maintain the participants' attention.

\subsubsection{Data acquisition}


Cleret de Langavant et al.

Reaction times (RTs) were recorded from the time that the target holder was announced (Figure 1) until the answer button was switched off using Expe software (Pallier, Dupoux, \& Jeannin, 1997), with a temporal resolution of $1 \mathrm{~ms}$. Pointing kinematics were recorded with a CODA tracking system (Charnwood Dynamics), which records the 3D trajectories of active LED markers with a spatial resolution of $0.1 \mathrm{~mm}$ at a frequency of $400 \mathrm{~Hz}$. A first LED marker (LED1) was attached to the right index fingertip of the participant. A second marker (LED2) was turned off and on by the answer button, allowing kinematic data acquisition to be synchronized to the onset of the participant's response.

\subsubsection{Data analyses}

Preprocessing of kinematics data. An exponential filter was used for each movement in the three dimensions of Cartesian space. The beginning of each movement was arbitrarily determined as the first point where velocity reached $5 \%$ of maximal velocity (maxvel). The end of each movement corresponded to the first point where velocity decreased below $5 \%$ of maxvel. Both movements directed at a wrong target or beginning before the end of the pointing instruction were rejected. In addition, $R T s$ deviating from more than 2 standard deviations (SD) from the mean by subject and by condition were replaced by the corresponding mean plus or minus 2 SD regarding the direction of their deviation. Overall, $96.5 \%$ of the initial data set was retained.

Spatio-temporal parameters. In order to check if the release of the answer button corresponded to the real onset of the pointing gesture, RTs data provided by the Expe software were corrected using the movement data from the 3D tracking system. The temporal gap between the release of the answer button (offset of LED2) and the effective beginning of the movement was added to the RT provided by Expe, yielding corrected reaction times. Because results in Experiment 1 and Experiment 2 were the same using either raw RT or corrected RT, with a temporal gap between the release of the answer button and the effective 
Cleret de Langavant et al.

beginning of the movement lasting around $60 \mathrm{~ms}$ on average, only the raw RT are displayed in the result section. Time to peak of maximal velocity (ttp) was defined as the time between the beginning of the movement and reaching maxvel. Time from peak of maximal velocity (tfp) was defined as the time between reaching maxvel and the end of the movement. For each pointing gesture directed at the target person, a sample of 20 points along the trajectory was isolated at equivalent temporal intervals. The sum of each distance between two of these consecutive points was used as a measure of the trajectory length for each gesture. For each interval, it was also possible to calculate the 3D instantaneous velocity. Average instantaneous velocity was then calculated for each point across the participant's data and within the target categories (body vs. objects).

Statistics. Analyses of variance (ANOVAs) were performed for each temporal parameter of the movement, with designated person (self vs. other) and target category (body vs. object) as the independent variables for the within-participant and within-item analyses.

\subsection{Results}

Similar results were found for the within-participant and within-item analyses; therefore, we only provide those of the former.

\subsubsection{Accuracy}

Pointing accuracy at the different targets was $99 \%$ overall without any difference between pointing at one's self and at another person's body and between pointing at body parts and at objects. Both target objects and body parts were properly identified by the addressee, showing the efficiency of the communicative exchange.

\subsubsection{Spatio-temporal parameters}

Reaction times. Pointing at one's self yielded shorter $R T$ s than pointing at another $(647 \pm 110$ ms versus $809 \pm 179$ ms respectively; $\mathrm{F}(1,19)=26.9$, p < 0.001). In addition, $R T s$ were shorter for pointing at objects compared to pointing at body parts $(\mathrm{F}(1,19)=10.6, \mathrm{p}=0.004)$. 
Cleret de Langavant et al.

There was an interaction between the designated person (self vs. other) and the category of the target (body vs. object) $(\mathrm{F}(1,19)=8.5, \mathrm{p}=0.009)$. Restricted analyses showed that participants displayed similar $R T s$ when pointing at objects or body parts on themselves $(\mathrm{F}(1$, 19) $=2.9 ; p>0.1$, whereas pointing at objects yielded shorter $R T$ s than pointing at body parts of another person $(\mathrm{F}(1,19)=14.4 ; p=0.001)$.

Movement parameters. Temporal parameters of the movements except $t$ tp and maxvel showed differences for pointing at one's self versus pointing at another person but did not differ for the object versus body contrast (Results are summarised in Table 1). There was no interaction for any of these parameters between the designated person and the category of the target. The length of finger trajectories was similar for gestures directed at the self, compared to those directed at another person. There was neither a significant effect of target category, nor an interaction between the above factors (all $\mathrm{p}>0.05$ ). As a consequence, average instant velocities for pointing at objects and at another person's body along the trajectories were similar (all p >0.05).

\subsection{Discussion}

Healthy participants showed longer $R T$ s for pointing at other people's body compared to objects, but no difference between pointing at own's body parts and pointing at objects on the self was observed. This result is consistent with heterotopagnosia, in which patients have difficulties in pointing at another person's body parts but not at objects or at the self (Auclair, Noulhiane, Raibaut, \& Amarenco, 2009; Cleret de Langavant, et al., 2009; Degos \& Bachoud-Lévi, 1998; Degos, et al., 1997; Felician, et al., 2003). Pointing at the self was faster than pointing at another person's body, presumably because of the afferent information coming from proprioception for pointing at the self in comparison to other bodies.

The lack of a modification of the movement parameters according to the target category in our pointing task contrasts with its presence in a previous experiment of reach-to-grasp 
Cleret de Langavant et al.

movements (Thompson, McConnell, Slocum, \& Bohan, 2007). This discrepancy may rely on the fact that our experimental set-up avoided any contact between the pointing finger and the target in contrast to the latter. However, it could also reflect a conceptual difference between communicative pointing and non-communicative reach-to-grasp gestures (Cleret de Langavant, et al., 2011; Sartori, et al., 2009). Consistently, grasping is flawless in patients with heterotopagnosia in contrast to pointing (Cleret de Langavant, Trinkler, Cesaro, \& Bachoud-Levi, 2009).

In addition, the difference between pointing at objects vs. pointing at body parts in this study was reflected in a difference in reaction times. Despite the role of the semantic category, such results were not observed in Bennett et al. (1998). This is presumably because the authors recorded their reaction times from an auditory signal following the target display, whereas we recorded reaction times from the identification of the target to the button release. Another influence on reaction time could come from the fact that we compared performance when pointing at real humans versus objects, whereas Bennett et al.'s used pointing at cards depicting living versus non-living items. Alternatively, the difference in RT for body parts and for objects could be due to the shape or size of the targets (Thompson, et al., 2007). The consequence of visuo-spatial characteristics of the other's body (being a whole) compared to objects (already discrete) could have influenced the pointing gesture. Experiment 2 was constructed as a control to check whether the RT difference stems from the communicative capacity of the other's body, rather than from a visuo-spatial feature linked to the target category. In this experiment the target person was replaced by a manikin.

\section{Experiment 2: Behavioural study of pointing at a manikin's body versus objects}

\subsection{Methods}

\subsubsection{Participants}


Cleret de Langavant et al.

Twenty right-handed (Oldfield, 1971) healthy volunteers (10 women, 10 men; mean age 28.0 \pm 5.7 years) were tested. Mean education level was $15.2 \pm 1.7$ years after primary school, and none had a history of neurological disease or treatment. Within this group, seven participants performed Experiment 1; among those, two began by Experiment 2. Local ethics-committee approval and the participants' written informed consent were obtained before the start of the study.

\subsubsection{Procedure and apparatus}

In Experiment 2, procedure and apparatus were similar to those used in Experiment 1 but the person facing the participant in Experiment 1 was replaced by a manikin. The manikin was sized like a real human. It could be a "male" or a "female", thus wearing a T-shirt on which male or female first names were written ("Luc" or "Jeanne" respectively). Ten participants pointed at a male manikin, 10 pointed at a female one. Objects were located like in Experiment 1 on the two flanking addressees, the manikin and the participant. Again, $80 \%$ of pointing gestures were directed either toward the participant or toward the manikin. The name of the target was provided by the flanking addressee that was designated. Twenty additional gestures were directed to either the left or right person's bodies, and thus the person at the other side was the addressee. The flanking persons could not be simultaneously the addressee and the target of the pointing gesture.

\subsubsection{Data acquisition and analyses}

A similar procedure was used as in Experiment 1. Overall, $90.2 \%$ of the initial data set was retained after outlier replacement. ANOVAs were run with the human figure (self vs. manikin) and target category (body vs. object) as the independent factors for the withinparticipant and within-item analyses.

\subsection{Results}

\subsubsection{Accuracy}


Cleret de Langavant et al.

The accuracy of participants pointing at the different targets was $99.5 \%$ without any difference between body parts and objects. Again, addressees properly identified the different targets.

\subsubsection{Spatio-temporal parameters}

All temporal parameters were slower when pointing at the manikin compared to when pointing at one's self. In addition, the lengths of the finger trajectories were shorter for gestures directed at the self compared to those directed at the manikin. Conversely, pointing at objects or at body parts yielded similar temporal and spatial parameters, including for $R T s$. There was no interaction between the human figure and the category of the target (Table 2). Finally, average instantaneous velocities for pointing at objects and at the manikin's body along the trajectories were similar (all $\mathrm{p}>0.05)$.

\subsection{Discussion}

There was no difference in $R T s$ between pointing at a manikin's body part and pointing at objects in Experiment 2. This result is in contrast with Experiment 1, where pointing at body parts to a person yielded longer RTs than pointing at objects. This reminds of heterotopagnosic patients who point at objects or at figurative representations of humans to the same extent (Cleret de Langavant, Trinkler, Cesaro, \& Bachoud-Levi, 2009; Felician, Ceccaldi, Didic, Thinus-Blanc, \& Poncet, 2003). The set-up of these experiments was similar, thereby ruling out any low level perceptual or linguistic difference as the origin of the vanishing of the RTs differential between objects and body parts of others: targets were the same as well as the procedure and the communicative exchange during pointing. Even the number of responses by the flanking addressees was kept similar. Moreover, objects and body parts remained located at the same place and were visible during the whole experiment and should have influenced the movements to the same extent. 
Cleret de Langavant et al.

Discrepancies between the results in Experiment 1 and Experiment 2 cannot be explained by their percentage of valid trials - which differ slightly (respectively 96.5\% and 90.2\%). Indeed, to assess such possibility, we compared the results of the two experiments by analyzing the first forty valid trials, directed at the other's body $(\mathrm{N}=20)$ or at objects $(\mathrm{N}=20)$, per participant. The results similarly show that RTs are shorter for objects compared to real other body parts in Experiment $1(\mathrm{~F}(1,19)=13.9, \mathrm{p}=0.001)$, but that the difference disappears in Experiment $2(\mathrm{~F}(1,19)=0.2, \mathrm{p}=0.7)$.

As a whole, the results of the Experiments 1 and 2 indicate that the body of other persons endows a specific status when it is the target of a communicative pointing gesture. This particular status does not rely on its tri-dimensional visuo-spatial features, but rather on its communicative capacity. This higher order information about the social value of the target specifically affects the planning phase of pointing, which is consistent with Glover's view (2004). Experiment 3 was designed to reveal the neural correlates of this "real body" versus "object" effect upon communicative pointing, and hence to identify which brain area could subserve the process of viewing another real person as a target object.

\section{Experiment 3: PET study of pointing at another person's body versus objects}

\subsection{Methods}

\subsubsection{Participants}

Ten right-handed (Oldfield, 1971) healthy male volunteers (mean age $25.8 \pm 5.2$ years) who had not participated in previous experiments were selected. Participants had a mean education level of $14.8 \pm 1.1$ years after primary school and no history of neurological disease or treatment. Local ethics-committee approval and the participants' written informed consent were obtained before the start of the PET study.

\subsubsection{Procedure and apparatus}


Cleret de Langavant et al.

The general design and apparatus were similar to those used in Experiment 1 except for a few adaptations required by the imaging procedure (Figure 2). The wide-open window of the PET-scan allowed us to record regional cerebral blood flow $(r C B F)$ of the participants while they directly looked at or communicated with real persons facing them. The participant in the PET-scan was instructed not to move except to execute the tasks. His head was immobilized with a rigid, individually fitted thermoplastic mask. His right index finger was positioned near an answer button. He wore headphones to listen to the instructions. Two addressees stood in front of him and wore T-shirts bearing their name: "Gilles" on the right and "Luc" on the left. In order to allow all involved persons to see all targets from their position and therefore to share attention upon those, only four target objects were used (battery, eraser, left lighter, right lighter; in French: pile, gomme, briquet gauche, briquet droit). They were stuck on a Plexiglas pane located between the right arm of the participant and the addressee "Gilles", and on the corresponding location of the body parts of so-called "Gilles" (head, neck, left shoulder and right shoulder; in French: tête, cou, épaule gauche, épaule droite) (Figure 2). Like in previous experiments 1 and 2, lexical frequencies of body parts and object names in French language were similar $(\mathrm{t}=1.14, \mathrm{p}>0.05)$.

$R T$ and accuracy were measured as in the previous experiment with an answer button. Spatial tracking was not recorded but the experiment was videotaped for subsequent controls. The $r C B F$ was measured under four conditions: (A) looking at an object; (B) pointing at an object without any intention to communicate; (C) pointing at an object while communicating with an addressee; and (D) pointing to another person's body parts while communicating with an addressee. The presentation of each condition was block designed. The main focus was put here on the comparison between conditions $\mathrm{C}$ and $\mathrm{D}$, which allows the search for the location of the brain area involved in pointing at body parts rather than objects, an area presumably 
Cleret de Langavant et al.

impaired in patients with heterotopagnosia. Other comparisons are published elsewhere (Cleret de Langavant et al., 2011).

A training phase in a supine position (5 trials for each condition) was first achieved to make the participants customized with the protocol. Participants were instructed before each block of the nature of the task and of the category of the target (body part or object). In particular, the participant and the addressees were told prior to the beginning of each block that pointing would be communicative or not. For each of the four conditions, blocks were repeated 3 times. Each block contained 24 randomised instructions leading to a total of 288 instructions (4 conditions X 3 repetitions X 24 instructions) for the whole experiment. The order of the four block conditions was kept constant across block repetitions within participant (e.g. ABCD ABCD ABCD or BADC BADC BADC), but it was counterbalanced across the participants (e.g. ABCD or BADC). Before each trial, the participant pushed down the answer button to hear the instruction and held it down until the gesture. According to this self-paced procedure, each participant controlled the rhythm for receiving trial instructions. Each auditory stimulus was composed of three elements: (i) an instruction to call the name of the designated addressee (e.g. "Gilles" or "Luc"); (ii) an instruction for the task (e.g. "show Gilles"); and finally (iii) the target ("the eraser" or "the nose") (Figure 2). When pointing was communicative, the designated addressee ("Gilles" or "Luc") said aloud the name of the target after the pointing gesture. Whereas both Gilles and Luc could be assigned the role of addressee, "Gilles" was the only target of pointing in order to keep the alignment between the object and body parts. During the two non-communicative conditions, the addressees were instructed not to open their eyes or react on hearing their names. After pointing, the participant heard the name of the target through headphones. The whole experiment was video-recorded to control whether participants understood the instructions and acted accordingly. 
Cleret de Langavant et al.

\subsubsection{Data acquisition}

$R T s$ were measured from the announcement of the name of the target until the answer button was switched off using Expe software, as in previous experiments. PET measurements were performed using a tomograph that allowed 3D acquisition of 63 transaxial slices (EXACTHR+; CTI-Siemens, Knoxville, Tennessee). Spatial resolution was $4.5 \mathrm{~mm}$ and $4.1 \mathrm{~mm}$ in the transaxial and axial directions, respectively. $r C B F$ images were acquired at 10 min apart, for $80 \mathrm{~s}$ after injection of $8 \mathrm{mCi} \mathrm{H}_{2}{ }^{15} \mathrm{O}$. Movements started $40 \mathrm{~s}$ before image acquisition. The number of pointing gestures recorded within a block was driven by the duration of the image acquisition. Once the image recorded, the task was interrupted by the external experimenter. This yielded $10.1 \pm 1.4$ gestures in one block. Each block corresponded to one image acquisition, yielding a total of 12 scans per participant.

\subsubsection{Data analysis}

$R T s$ were subjected to ANOVA analysis using target category (body parts vs. objects) in communicative pointing as the independent variable for the within-participant and withinitem analysis. Image analysis was performed using statistical parametric mapping (SPM2; http://www.fil.ion.ucl.ac.uk/spm/). The 12 images obtained for each participant were realigned, normalized to Montreal Neurological Institute space, and smoothed with a Gaussian kernel of 8-mm full width at half maximum. Images obtained during pointing at the real body were compared to those acquired during pointing at objects. Voxels were considered significant at $\mathrm{p}_{\text {uncorrected }}<0.001$. The minimal cluster size was set at 10 contiguous voxels.

\subsection{Results}

\subsubsection{Accuracy}

Participants achieved slightly different number of pointing gestures during the experiment and never reached the maximum number of instructions. They pointed on average at $45.7 \pm 2.8$ 
Cleret de Langavant et al.

objects and $46.3 \pm 2.6$ at another's body parts $(t=-0.4, p>0.05)$. Pointing accuracy was $100 \%$. In concordance with the previous behavioural experiments, the addressees correctly named the designated target.

\subsubsection{Reaction times}

Communicative pointing at objects yielded shorter $R T$ s than communicative pointing at another person's body parts $(959.1 \pm 141 \mathrm{~ms}$ vs. $998.6 \pm 133 \mathrm{~ms}$, respectively; $\mathrm{F}(1,9)=6.7, p$ $=0.029$ ), as in Experiment 1. However, as published elsewhere (Cleret de Langavant et al., 2011), RTs for non-communicative pointing at objects $(993.2 \pm 155 \mathrm{~ms})$ were not different from those of communicative pointing at the same objects $(F(1,9)=2.5 ; p>0.05)$.

\subsubsection{Regional cerebral blood-flow variations}

Pointing at another person's body compared to pointing at objects (body - object) activated the precuneus bilaterally, the right superior medial prefrontal cortex, the posterior part of the left intra-parietal sulcus (LpIPS), the left cerebellum and the left middle occipital gyrus corresponding to the Extrastriate Body Area (EBA, Downing et al, 2001) (Table 3 and Figure 3). Within this network, the comparison of the modulations of $\mathrm{rCBF}$ in the four different conditions (look at objects, non communicative pointing at objects, communicative pointing at objects, and communicative pointing at body parts) showed that maximal modulation was obtained within the communicative pointing tasks and changed according to the nature of the target (Figure 3). The reverse comparison (object - body) did not yield activations in the left posterior parietal cortex, but it revealed activations in several other areas including the right middle temporal, the right superior frontal, the right inferior parietal and the left inferior frontal gyri (Table 4 and Figure 4).

\subsection{Discussion}

This PET experiment documents the neural correlates of the difference between pointing at another person's body and pointing at objects, in a task involving a genuine communicative 
Cleret de Langavant et al.

exchange with an addressee and a real human target, which was directly visible for the pointing participant lying onto the scanner bed. Accordingly, the behavioural measures (RT) in Experiment 3 reproduce the results of Experiment 1, where pointing at objects is faster than pointing at body parts. As expected, the difference in target category in our comparison of communicative pointing at body parts and communicative pointing at objects identified a small set of areas including the left posterior parietal region, the latter being the one impaired for pointing at other's body but not at objects in heterotopagnosia (Auclair, et al., 2009; Cleret de Langavant, et al., 2009; Degos \& Bachoud-Lévi, 1998; Degos, et al., 1997; Felician, et al., 2003).

Although the two main conditions of interest (pointing at another person's body and pointing at objects) involved various components including language processing for understanding the verbal instruction and the addressee's answer, motor processing for achieving the pointing gesture, spatial processing, etc., the conditions only differ one from the other on the choice of the target, whether body parts or objects. As a consequence, the comparison of the rCBF variations between the above conditions disentangles the location of brain areas used for body parts and objects while pointing. As pointing movements and language processing were similar in both conditions, motor areas and language areas (i.e. Broca's or Wernicke's areas) were not expected to be differently activated in pointing at body parts and pointing at objects conditions. Thus, the consistency between the activation of the LpIPS in Experiment 3 and its lesion in heterotopagnosia suggests its genuine role in the communication about other's body through pointing.

\section{General discussion}

Pointing at another person's body is socially inappropriate and appears almost impossible in patients with heterotopagnosia, perhaps because the body of another human is usually 
Cleret de Langavant et al.

considered as a person to communicate with and not as an object. In a pointing paradigm inspired by the testing of patients with heterotopagnosia, we explored whether the category of the target influences the pointing gesture. We assessed in healthy participants the behavioural and neural correlates of communicative pointing directed at one's self, at another person's body parts, at a manikin's body parts and at objects located on these bodies. Pointing directed toward the self was always faster than pointing to somebody else (real person or manikin). However, pointing at objects was faster than pointing at body parts when objects were located on another person's body, but not on the manikin or on the participant's own body. This indicates that the difference observed between pointing at body parts and pointing at objects does not relate to the basic visuo-spatial features of the human body but rather to some specific feature only present in the body of other people. Presumably the other person is identified as a conspecific having a capacity for communication. Finally, consistently with the region lesionned in heterotopagnosia, the PET-study unveiled the activation of the LpIPS during pointing at another person's body, but not during pointing at objects. This suggests that a specific representation is attached to the body of a real person when communicating through pointing.

\subsection{The specificity of another person's body as a pointed target}

Consistently with heterotopagnosia, in which patients have difficulties in pointing at body parts but not at objects (Auclair, et al., 2009; Cleret de Langavant, et al., 2009; Degos \& Bachoud-Lévi, 1998; Degos, et al., 1997; Felician, et al., 2003), healthy participants were slower when pointing at other's body parts than at objects on the same location (Experiment 1) but such difference vanished when the real person facing them was replaced by a manikin (Experiment 2), all other parameters being equalised. As a whole, the results of the behavioural experiments 1 and 2 indicate that the body of the real person endows a specific status which does not rely on its tri-dimensional visuo-spatial features. This might explain 
Cleret de Langavant et al.

why previous studies of healthy participants' movement performance using figurative targets obtained a reverse effect. Indeed, when participants were asked to reach-to-grasp and pair together pictures of either living or non-living things, movements were faster for pairing together the pictures of living things (Bennett et al., 1998). Likewise, healthy volunteers showed shorter $R T$ s for localizing with a track-ball human body parts depicted on realistic videos compared to drawings (Felician et al., 2009). These results obtained in healthy participants do not fit with the behaviour of patients with heterotopagnosia who easily point at objects or figurative representations of the body. However the above experiments (Bennett et al., 1998; Felician et al., 2009) not only used figurative representations, and not real persons, but also involved a non-communicative set-up. Therefore, the discrepancy between our study and previous ones might not rely only on the specificity of the real human body as a target, but also on the communicative set-up of pointing. The consistency between our results, the behavioural pattern of heterotopagnosia (Auclair, et al., 2009; Cleret de Langavant, et al., 2009; Degos \& Bachoud-Lévi, 1998; Degos, et al., 1997; Felician, et al., 2003) and the common reticence for pointing at another persons' body (Tallis, 2010) suggests that specific brain processes are recruited during a communicative pointing task when using the body of another real person as a target. Therefore, the neural processes needed to achieve a pointing gesture directed at a communicative body part should also activate regions impaired in heterotopagnosia.

\subsection{Neural correlates of pointing at another person's body}

The comparison of pointing at another person's body parts versus pointing at objects revealed a bilateral brain network including the LpIPS (Experiment 3, contrast: body - object, Figure

3, Table 3), a region which is usually impaired in heterotopagnosia (Auclair, et al., 2009; Cleret de Langavant, et al., 2009; Degos \& Bachoud-Lévi, 1998; Degos, et al., 1997; Felician, et al., 2003). It is noteworthy that, despite previous studies of heterotopagnosia provided 
Cleret de Langavant et al.

either low definition neuroimaging data of strokes (Auclair, et al., 2009; Cleret de Langavant, et al., 2009; Degos \& Bachoud-Lévi, 1998; Degos, et al., 1997; Felician, et al., 2003), or better quality imaging of patients suffering from pathologies of different aetiologies (degenerative disease (Auclair, et al., 2009; Cleret de Langavant, et al., 2009; Degos \& Bachoud-Lévi, 1998; Degos, et al., 1997; Felician, et al., 2003), large haemorrhage in Auclair, et al., 2009), they all included impairment in left posterior parietal cortex overlapping the LpIPS.

The LpIPS area differs from previously reported body-related brain areas in the region of the left parietal lobe (Figure 5; see (Berlucchi \& Aglioti, 2009; Longo, Azanon, \& Haggard, 2010), for reviews). This suggests that the latter body areas correspond to levels of body knowledge (Schwoebel \& Coslett, 2005; Sirigu, Grafman, Bressler, \& Sunderland, 1991) that are either not critical in the present pointing task or are activated both when pointing at bodies and when pointing at objects. Indeed, there is no need for activation of the body schema that represents one's own moving body in space (Corradi-Dell'Acqua, Tomasino, \& Fink, 2009) or of lexical and semantic abilities related to the human body (Le Clec'H, et al., 2000; McCrea, 2007) in our pointing task. Also, the structural and visuo-spatial representation of the human body (Corradi-Dell'Acqua, et al., 2009) cannot account for the functional difference between pointing at another person's body parts and pointing at objects, because the same structural body representation should be equally used for the real human body and the manikin. Finally, the parieto-frontal mirror neuron network activated when watching or executing the same body action (Gallese, Fadiga, Fogassi, \& Rizzolatti, 1996; Kilner, Marchant, \& Frith, 2009; Kilner, Neal, Weiskopf, Friston, \& Frith, 2009; Rizzolatti \& Craighero, 2004), and the temporo-parietal junction, which subserves the sense of being localized within one's own physical body (Blanke \& Arzy, 2005; Kahane, Hoffmann, Minotti, \& Berthoz, 2003; 
Cleret de Langavant et al.

Lenggenhager, Tadi, Metzinger, \& Blanke, 2007), were not found in our study, presumably because such body areas were similarly active (or inactive) during both conditions.

Because all above cited body knowledge areas are classically activated for figurative human body representations, the LpIPS in our study might relate to the real human body. However, watching the living human body does not by itself elicit activation in the LpIPS: the passive observation of grasping actions executed by a real hand compared to a virtual hand elicited right - and not left - posterior parietal activation in a PET study (Perani, et al., 2001). Rather, the LpIPS activation might occur in the task of pointing at human body parts, and specifically those belonging to another real person. Indeed, in an fMRI study where participants pointed at their own body parts or at directions in the room, activations were found in the left superior parietal lobule and in the left intra-parietal sulcus, but in a more anterior location than the LpIPS (Figure 5) (Felician, et al., 2004). The left parietal activations found when pointing at one's self (Felician, et al., 2004) might therefore correspond to the lesion causing autotopagnosia, the inability to point at one's own body parts (Felician, Ceccaldi, Didic, Thinus-Blanc, \& Poncet, 2003; Pick, 1922; Schwoebel \& Coslett, 2005; Schwoebel, Coslett, \& Buxbaum, 2001). In addition, localizing body parts, through the use of a track-ball but without any communicative intention, onto an external figurative body of human species rather activates the left angular gyrus (Felician et al, 2009). Finally, the rCBF modulations in the LpIPS in the different conditions of our study suggest that the communicative context of pointing (see Figure 3) favours the discrimination found between another person's body target and objects compared to the non-communicative context. Altogether, these results suggest that the LpIPS processes a representation dedicated to the body of another real person in a context of communicative pointing.

In addition, pointing at another person's body activated a left middle occipital area which probably corresponds to the Extrastriate Body Area (EBA, (Downing, Jiang, Shuman, \& 
Cleret de Langavant et al.

Kanwisher, 2001), the left and right precuneus, and the left superior medial prefrontal (Table 3 and Figure 3). This network is dedicated to social cognition and to the representation of the human body. For example, the EBA is usually activated when perceiving visual representations of the human body (pictures, drawings, videos) but not objects or places ((Downing, et al., 2001) and when localizing figurative human body parts (Felician et al, 2009). Our study shows that it can be activated not only when perceiving human figures but also real humans. The precuneus is a highly connected region (Cavanna \& Trimble, 2006) involved in self-centred cognitive processes, such as visuospatial mental imagery (Culham, et al., 1998; Hanakawa, et al., 2003; Le, Pardo, \& Hu, 1998), episodic memory retrieval (Addis, McIntosh, Moscovitch, Crawley, \& McAndrews, 2004; Lundstrom, et al., 2003), and both first-person (Vogeley \& Fink, 2003) and third-person perspective-taking (Ruby \& Decety, 2001).The left superior medial prefrontal activation could reflect processes of motivation (Habib, 2004; Paus, 2001), internally-driven control of attention and action (Nachev, Kennard, \& Husain, 2008), and self-consciousness (Vogt \& Laureys, 2005). Therefore, activation of the precuneus and the superior medial prefrontal cortex might reveal enhanced self-related processes while communicating about another person's body with an alter ego (Felician et al, 2009).

Several brain areas revealed by the reverse contrast (contrast object - body, Table 4 and Figure 4) might also participate while pointing at another person's body parts. Indeed, the variations of $\mathrm{rCBF}$ in the right middle temporal gyrus might correspond to the processing of specific object (Acres, Taylor, Moss, Stamatakis, \& Tyler, 2009) while pointing at objects, or alternately to the inhibition of social perception areas related to the body of another person (Allison, Puce, \& McCarthy, 2000). Interestingly, the variations of rCBF for the different targets (object vs. body) in the right middle temporal, the right inferior parietal and in the right superior frontal regions are observed for the two conditions of communicative pointing, 
Cleret de Langavant et al.

but not for looking at objects and non-communicative pointing at objects (Figure 4). This suggests that these areas may participate in the specific interaction at stake between the communicative relationship with an addressee and the communicative ability of the other's body during the task of pointing at another person's body parts. Conversely, the decrease of rCBF in the left inferior frontal region (Figure 4) might imply an inhibitory process specific to the body of another person per se. Future studies are needed to understand the role of these areas in the task of pointing at objects or body parts and to further test their specificity for communicative pointing or other social contexts.

\subsection{A communicative task and a communicative target}

Pointing at other's body parts involves both a communicative task and a communicative target. Both are presumably equally crucial for the behavioural and neural results reported here. Indeed, we previously showed that communication through pointing implies a spatial reshaping of the gesture, according to the position of the addressee's body and perspective (Cleret de Langavant et al., 2011). Consistently, the communicative intention affects the kinematics of a reaching movement (Sartori, et al., 2009).

Now, we have shown the link between the communicative nature of the pointing task and the communicative capacity held by the body of a real human. The analysis of the triadic communicative structure of pointing offers a theoretical framework for this hypothesis. While pointing, one subject communicates with another subject about the target object. Therefore, pointing and speech share a similar triadic relationship between three elements: both the first person "I" and the second person "you" communicate about a non-communicative object, the third person "it" or "him/her", which assumes a non-subject status (Benveniste, 1966; Cleret de Langavant, et al., 2009; Degos, et al., 1997; Stawarska, 2009). According to this triadic frame, the human body of other persons could endow two different statuses depending on the circumstances: a communicative subject "you" or a non-communicative object "him/her". 
Cleret de Langavant et al.

Conversely, non-communicative manikins or other figurative representations of the human body could only be considered as objects. Given the fact that humans are spontaneously engaged in communication and in social behaviour (Schilbach, Eickhoff, Rotarska-Jagiela, Fink, \& Vogeley, 2008; Watzlawick, Helminck Beavin, \& Jackson, 1967), they might preferentially consider their conspecifics as subjects "you" to communicate with. Viewing other humans as subjects is a process that might participate to joint action behaviour effects (Atmaca, Sebanz, \& Knoblich, 2011), where an individual maintains a copy of another close human's action even if cooperation is not explicitly required. The identification of the second person "you" would require the building of a heterocentric reference frame for imagining this person's point of view (Cleret de Langavant et al., 2011). However, in other circumstances, such as in science, art, or publicity, humans might also consider the body of their conspecifics as objects to communicate about. Critically, pointing at another person's body requires both opposite views onto the other person's body - communicative subject and non-communicative object - to be achieved. Maintaining simultaneously these two alternative views might impose a supplementary cognitive cost, thus explaining why pointing at another person's body is more difficult than pointing at objects in both healthy subjects and patients with heterotopagnosia. The behavioural differences according to the target we observed in experiments 1 and 3 , in the preparatory phase (RT) of the movement further suggest that ascribing these body parts the status of objects requires additional processing from the early perceptual stages of the pointing program (Desmurget, Pelisson, Rossetti, \& Prablanc, 1998; Jeannerod, 1988) in a dedicated brain network. In sum, both our previous study on the communicative aspect of pointing (Cleret de Langavant et al., 2011), and the present study on the communicative influence of the target body upon pointing, suggest that the communication aspect affects the planning phase of the pointing movement. This influence is evidenced by building a specific reference frame in the former study and by specific RT 
Cleret de Langavant et al.

modifications in the latter. We propose that ascribing the status of an object or of an addressee to another person's body takes place during the planning phase of the movement. In addition, we suggest that the combination of a communicative pointing task with a communicative human target is responsible for the activation of the LpIPS in Experiment 3. The LpIPS would process the living body of another person usually addressed as a subject "you" and ascribe to it the status of an object "him/her" during communicative pointing. An interesting development of this theory would be that the LpIPS regulates the ascription of the addressee's status when confronted with any real body. A preliminary process within this area would be needed for recognizing the addressee before any attempted communication.

\section{Conclusions}

In experimental conditions, the shape of the human body can be embodied through different means: either figurative (videos, pictures...) or by real living human. The brain certainly differentiates between those forms, given the fact that humans do not communicate with nonliving representations of a human (e.g. a manikin in a store window or a person speaking on the T.V.). Accordingly, the present study brings evidence that within the communicative context of pointing, the brain differentiates between real humans and objects but not between a manikin and objects. Moreover, our results suggest that the pointing deficit in patients with heterotopagnosia and the common reticence for pointing at another person's body in healthy subjects could rely on the involvement of a costly process necessary to view another subject's body as an object (Tallis, 2010), particularly in the communicative context of pointing. The LpIPS would regulate the ascription of the status of subject and object to the living human body in communicative pointing. Further explorations are needed to explore its role in other social or non-social contexts.

\section{Competing interest statement}


Cleret de Langavant et al.

The authors declare no conflict of interest.

\section{Acknowledgements}

LCL was supported by an APHP-CANAM grant. IT was supported by an HFSP (Human Frontiers Science Program) and Swiss National Funds Fellowship for prospective researchers. 
Cleret de Langavant et al.

\section{References}

Acres, K., Taylor, K. I., Moss, H. E., Stamatakis, E. A., \& Tyler, L. K. (2009). Complementary hemispheric asymmetries in object naming and recognition: a voxelbased correlational study. Neuropsychologia, 47(8-9), 1836-1843.

Addis, D. R., McIntosh, A. R., Moscovitch, M., Crawley, A. P., \& McAndrews, M. P. (2004). Characterizing spatial and temporal features of autobiographical memory retrieval networks: a partial least squares approach. NeuroImage, 23(4), 1460-1471.

Allison, T., Puce, A., \& McCarthy, G. (2000). Social perception from visual cues: role of the STS region. Trends in Cognitive Sciences, 4, 267-278.

Auclair, L., Noulhiane, M., Raibaut, P., \& Amarenco, G. (2009). Where are your body parts? A pure case of heterotopagnosia following left parietal stroke. Neurocase, 15(6), 459465.

Baron-Cohen, S. (1989). Perceptual role taking and protodeclarative pointing in autism. British Journal of Developmental Psychology, 7, 113-127.

Baron-Cohen, S. (1995). Mindblindness: an essay on autism and theory of mind. Cambridge: MIT press.

Bennett, K. M., Thomas, J. I., Jervis, C., \& Castiello, U. (1998). Upper limb movement differentiation according to taxonomic semantic category. NeuroReport, 9(2), 255262.

Benveniste, E. (1966). Structure des relations de personne dans le verbe. Problèmes de linguistique générale, I. Paris: Gallimard.

Berlucchi, G., \& Aglioti, S. M. (2009). The body in the brain revisited. Experimental Brain Research.

Blanke, O., \& Arzy, S. (2005). The out-of-body experience: disturbed self-processing at the temporo-parietal junction. Neuroscientist, 11(1), 16-24.

Castiello, U. (2005). The neuroscience of grasping. Nat Rev Neurosci, 6(9), 726-736.

Cavanna, A. E., \& Trimble, M. R. (2006). The precuneus: a review of its functional anatomy and behavioural correlates. Brain, 129(Pt 3), 564-583.

Charman, T. (2003). Why is joint attention a pivotal skill in autism? Philosophical Transactions of the Royal Society of London B Biological Sciences, 358(1430), 315324.

Cleret de Langavant, L., Remy, P., Trinkler, I., McIntyre, J., Dupoux, E., Berthoz, A., et al. (2011). Behavioral and neural correlates of communication via pointing. PLoS One, 6(3), e17719. 
Cleret de Langavant et al.

Cleret de Langavant, L., Trinkler, I., Cesaro, P., \& Bachoud-Levi, A. C. (2009). Heterotopagnosia: When I point at parts of your body. Neuropsychologia, 47(7), 17451755 .

Corradi-Dell'Acqua, C., Tomasino, B., \& Fink, G. R. (2009). What is the position of an arm relative to the body? Neural correlates of body schema and body structural description. Journal of Neuroscience, 29(13), 4162-4171.

Culham, J. C., Brandt, S. A., Cavanagh, P., Kanwisher, N. G., Dale, A. M., \& Tootell, R. B. (1998). Cortical fMRI activation produced by attentive tracking of moving targets. Journal of Neurophysiology, 80(5), 2657-2670.

Degos, J.-D., \& Bachoud-Lévi, A.-C. (1998). La désignation et son objet ; pour une neuropsychologie de l'objectivation. Rev Neurol(154), 283-290.

Degos, J.-D., Bachoud-Lévi, A.-C., Ergis, A.-M., Petrissans, J.-L., \& Cesaro, P. (1997). Selective inability to point to extrapersonal targets after left posterior parietal lesion: an objectivisation disorder? Neurocase, 3, 31-39.

Desmurget, M., Pelisson, D., Rossetti, Y., \& Prablanc, C. (1998). From eye to hand: planning goal-directed movements. Neuroscience and Biobehavioral Reviews, 22(6), 761-788.

Downing, P. E., Jiang, Y., Shuman, M., \& Kanwisher, N. (2001). A cortical area selective for visual processing of the human body. Science, 293(5539), 2470-2473.

Felician, O., Anton, J. L., Nazarian, B., Roth, M., Roll, J. P., \& Romaiguere, P. (2009). Where is your shoulder? Neural correlates of localizing others' body parts. Neuropsychologia, 47(8-9), 1909-1916.

Felician, O., Ceccaldi, M., Didic, M., Thinus-Blanc, C., \& Poncet, M. (2003). Pointing to body parts: a double dissociation study. Neuropsychologia, 41, 1307-1316.

Felician, O., Romaiguere, P., Anton, J. L., Nazarian, B., Roth, M., Poncet, M., et al. (2004). The role of human left superior parietal lobule in body part localization. Annals of Neurology, 55(5), 749-751.

Gallese, V., Fadiga, L., Fogassi, L., \& Rizzolatti, G. (1996). Action recognition in the premotor cortex. Brain, 119(2), 593-609.

Habib, M. (2004). Athymhormia and disorders of motivation in Basal Ganglia disease. Journal of Neuropsychiatry and Clinical Neurosciences, 16(4), 509-524.

Hanakawa, T., Immisch, I., Toma, K., Dimyan, M. A., Van Gelderen, P., \& Hallett, M. (2003). Functional properties of brain areas associated with motor execution and imagery. Journal of Neurophysiology, 89(2), 989-1002.

Jeannerod, M. (1988). Motor Control: Concepts and Issues In Wiley (Ed.), The Neural and Behavioural Organization of Goal-Directed Movements. New York.

Kahane, P., Hoffmann, D., Minotti, L., \& Berthoz, A. (2003). Reappraisal of the human vestibular cortex by cortical electrical stimulation study. Annals of Neurology, 54, 615-624. 
Cleret de Langavant et al.

Kilner, J. M., Marchant, J. L., \& Frith, C. D. (2009). Relationship between activity in human primary motor cortex during action observation and the mirror neuron system. PLoS One, 4(3), e4925.

Kilner, J. M., Neal, A., Weiskopf, N., Friston, K. J., \& Frith, C. D. (2009). Evidence of mirror neurons in human inferior frontal gyrus. Journal of Neuroscience, 29(32), 1015310159.

Kita, S. (2002). Pointing: A Foundational Building Block of Human Communication. In S. Kita (Ed.), Pointing, where Language, Culture and Cognition Meet. (pp. 1-8). London: Lawrence Erlbaum Associates.

Le Clec'H, G., Dehaene, S., Cohen, L., Mehler, J., Dupoux, E., Poline, J. B., et al. (2000). Distinct cortical areas for names of numbers and body parts independent of language and input modality. Neuroimage, 12(4), 381-391.

Le, T. H., Pardo, J. V., \& Hu, X. (1998). 4 T-fMRI study of nonspatial shifting of selective attention: cerebellar and parietal contributions. Journal of Neurophysiology, 79(3), $1535-1548$.

Lenggenhager, B., Tadi, T., Metzinger, T., \& Blanke, O. (2007). Video ergo sum: manipulating bodily self-consciousness. Science, 317, 1096-1099.

Longo, M. R., Azanon, E., \& Haggard, P. (2010). More than skin deep: Body representation beyond primary somatosensory cortex. Neuropsychologia, 48(3), 655-668.

Lundstrom, B. N., Petersson, K. M., Andersson, J., Johansson, M., Fransson, P., \& Ingvar, M. (2003). Isolating the retrieval of imagined pictures during episodic memory: activation of the left precuneus and left prefrontal cortex. NeuroImage, 20(4), 1934-1943.

McCrea, S. M. (2007). A functional magnetic resonance imaging study of the body schema using full human line-drawing figures in an on-line verbal naming and localization task of single body part words. Behavioural Brain Research, 180(2), 235-240.

Nachev, P., Kennard, C., \& Husain, M. (2008). Functional role of the supplementary and presupplementary motor areas. Nature Reviews Neuroscience, 9(11), 856-869.

Oldfield, R. C. (1971). The assessment and analysis of handedness: the Edinburgh Inventory. Neuropsychologia, 9, 97-113.

Pallier, C., Dupoux, E., \& Jeannin, X. (1997). Expe: an expandable programming language for on-line psychological experiments. Behavior Research Methods, Instruments and Computers, 29(3), 322-327.

Paus, T. (2001). Primate anterior cingulate cortex: where motor control, drive and cognition interface. Nat Rev Neurosci, 2(6), 417-424.

Perani, D., Fazio, F., Borghese, N. A., Tettamanti, M., Ferrari, S., Decety, J., et al. (2001). Different brain correlates for watching real and virtual hand actions. NeuroImage, 14(3), 749-758. 
Cleret de Langavant et al.

Rizzolatti, G., \& Craighero, L. (2004). The mirror-neuron system. Annual Reviews of Neuroscience, 27, 169-192.

Ruby, P., \& Decety, J. (2001). Effect of subjective perspective taking during simulation of action: a PET investigation of agency. Nature Neuroscience, 4(5), 546-550.

Sartori, L., Becchio, C., Bara, B. G., \& Castiello, U. (2009). Does the intention to communicate affect action kinematics? Conscious Cogn, 18, 766-772.

Schilbach, L., Eickhoff, S. B., Rotarska-Jagiela, A., Fink, G. R., \& Vogeley, K. (2008). Minds at rest? Social cognition as the default mode of cognizing and its putative relationship to the "default system" of the brain. Consciousness and Cognition, 17, 457-467.

Schwoebel, J., \& Coslett, H., B. (2005). Evidence for multiple, distinct representations of the human body. Journal of Cognitive Neuroscience, 17(4), 543-553.

Sirigu, A., Grafman, J., Bressler, K., \& Sunderland, T. (1991). Multiple representations contribute to the body knowledge processing; evidence from a case of autotopoagnosia. Brain, 114, 629-642.

Stawarska, B. (2009). Between You and I: Dialogical Phenomenology. Athens: Ohio University Press.

Tallis, R. C. (Ed.). (2010). Michelangelo's Finger. An exploration of everyday transcendence. New Haven: Yale University Press.

Thompson, S. G., McConnell, D. S., Slocum, J. S., \& Bohan, M. (2007). Kinematic analysis of multiple constraints on a pointing task. Human movement science, 26(1), 11-26.

Tomasello, M., Carpenter, M., Call, J., Behne, T., \& Moll, H. (2005). Understanding and sharing intentions: the origins of cultural cognition. Behavioral and brain sciences, 28(5), 675-691; discussion 691-735.

Vogeley, K., \& Fink, G., R. (2003). Neural correlates of the first-person-perspective. Trends in Cognitive Science, 7(1), 38-42

Vogt, B. A., \& Laureys, S. (2005). Posterior cingulate, precuneal and retrosplenial cortices: cytology and components of the neural network correlates of consciousness. Progress in brain research, 150, 205-217.

Watzlawick, P., Helminck Beavin, J., \& Jackson, D. D. (1967). Pragmatics of Human Communication. A study of Interactional Patterns, Pathologies, and Paradoxes. NewYork: W.W. Norton \& Company, inc. 
Cleret de Langavant et al.

\section{Table legends}

Table 1: Spatio-temporal parameters for pointing at body parts and at objects located on the self or on another person.

$R T$ : reaction time (ms); ttp: time to peak of maximal velocity (ms); tfp: time from peak of maximal velocity (ms); dur: duration of the movement (ms); maxvel: maximal velocity (m/s); traj: length of finger trajectory $(\mathrm{mm})$; ns: not significant $(p>0.05)$; SO: Self $x$ Other; OB: Object x Body. Values shown are means (SD: standard deviation).

Table 2: Spatio-temporal parameters for pointing at body parts and at objects located on the self or on a manikin's body.

$R T$ : reaction time (ms); ttp: time to peak of maximal velocity (ms); tfp: time from peak of maximal velocity (ms); dur: duration of the movement (ms); maxvel: maximal velocity (m/s); traj: length of finger trajectory $(\mathrm{mm})$; ns: not significant $(p>0.05)$; SM: Self x Manikin; OB: Object x Body. Values shown are means (SD: standard deviations).

Table 3: Comparison between pointing at another person's body and pointing at objects (body - object).

BA: Brodmann area; MNI: Montreal Neurological Institute brain atlas.

Threshold of analysis $p_{\text {uncorrected }}<0.001$. Cluster size $>10$ contiguous voxels. * Area corresponding to the Extrastriate Body Area (Cluster size $=4$ voxels).

Table 4: Comparison between pointing at objects and pointing at another person's body (object - body).

BA: Brodmann area; MNI: Montreal Neurological Institute brain atlas.

Threshold of analysis $p_{\text {uncorrected }}<0.001$. Cluster size $>10$ contiguous voxels. $*$ The anatomical location of this area could be either in the parahippocampal gyrus or in the pons. 
Cleret de Langavant et al.

\section{Figure legends}

\section{Figure 1: Set up (a \& b) and timeline for a pointing trial (c) in Experiment 1 and 2.}

(a) The persons involved in Experiment 1 wore different objects located on different body parts (left panel). (b) The participant (i.e. the one who points at) and three other persons were seated in a square format (right panel). The three other persons became randomly in turn either addressees or targets. Analysis focused on pointing gestures towards the body of the person facing the participant (50\% body parts, $50 \%$ objects). (c) Pointing instructions provided through headphones had three components: (i) identification of the addressee (e.g. "show Luc"); (ii) identification of the target (e.g. "the nose" or "the glasses"); (iii) identification of the holder of the target (e.g. "of Jeanne"). Reaction times (RT) were measured from the beginning of the naming of the holder of the target.

\section{Figure 2: Set up (a \& b) and timeline for a pointing trial (c) in Experiment 3.}

(a) The participant faced two persons standing on stools in front of him, on either side of the scanner bed. Both were potential addressees. The participant was instructed via headphones to point at body parts of the right person (Gilles) or at an object located on a vertical transparent Plexiglas pane in front of Gilles. (b) The participant could see from the scanner bed the different targets. The body parts (head, neck and shoulders) and the objects (eraser, battery and lighters) were spatially matched, two by two, from the participant's point of view (eraser/head, battery/neck, lighters/shoulders). The addressees could have their eyes either closed in non-communicative conditions (looking or non-communicative pointing at objects) or open in communicative conditions (communicative pointing at an object or a real body part). This precluded any communication through pointing in the closed-eyes condition. (c) The verbal instruction was composed of three elements: i) instruction for calling an addressee, ii) instruction for pointing, iii) the name of the target. 
Cleret de Langavant et al.

Figure 3: Specificity of the brain network for pointing at another person's body: contrast (body - object). Activations for the contrast (body - object), in communicative context, were plotted onto a magnetic resonance-imaging template (MRIcroN, www.mricro.com): left posterior intraparietal sulcus LpIPS (a, transversal plane), left Extrastriate Body Area EBA (b, transversal plane), right middle cingulum (c, sagittal plane), and both precuneus (d, coronal plane) $\left(P_{\text {uncorrected }}<0.001\right)$. Regional cerebral blood flow $(\mathrm{rCBF})$ variations in this network were examined in the four conditions. Comparison of $\mathrm{rCBF}$ variations between looking at objects (gaze object), non-communicative pointing at objects (ncp object), pointing at objects (cp object), and pointing at body parts (cp body), suggests that this network is sensitive to the nature of the target whether it is a body part or an object, but also to the communicative value of pointing.

Figure 4: Specificity of the brain network for pointing at another person's body: contrast (object - body). Activations for the contrast (object - body), in communicative context, were plotted onto a magnetic resonance-imaging template and presented with coronal slices (MRIcroN, www.mricro.com) in the right middle temporal (a), the left inferior frontal gyri (b), the right superior frontal (c) and the right inferior parietal (d) regions. Regional cerebral blood flow (rCBF) variations in this network were examined in the four conditions: looking at objects (gaze object), non-communicative pointing at objects (ncp object), pointing at objects (cp object), and pointing at body parts (cp body).

Figure 5: Topography of previous body-related activations in the region of the left parietal cortex and the lesion found in heterotopagnosia.

The activation foci of functional imaging studies using different body-related tasks (tapping into different systems of body representation) were plotted onto a template of the left human 
Cleret de Langavant et al.

hemisphere (PALS Atlas, Caret software v5.61, http://brainmap.wustl.edu/caret.html) presented in dorso-lateral (top, a) and dorso-posterior (bottom, b) views. We focused on activations in the region of the left parietal cortex. Tasks were handedness judgment of an arm mentally rotated onto an allocentric space (a) (Corradi-Dell'Acqua, et al., 2009); handedness judgment during mental rotation of a representation of an arm onto a self-egocentric representation of the body (b) (Corradi-Dell'Acqua, et al., 2009); perception of figurative human body and body parts (Downing, et al., 2001); pointing without communication at own body parts (Felician, et al., 2004); pointing without communication of body parts and figurative representations of the human body (Felician, et al., 2009); judgment of the relative position of a named body part on a imagined standing person (Le Clec'H, et al., 2000); and matching body-part name with one body-part location on a black and white drawing (McCrea, 2007). In addition, the location of the lesion in three patients with heterotopagnosia (Cleret de Langavant, et al., 2009) and the location of the LpIPS found in the present study are also indicated.

CS: central sulcus; STS: superior temporal sulcus; aIPS: anterior intraparietal sulcus; pIPS: posterior intra parietal sulcus; LpIPS Left posterior intra parietal sulcus; Ant: anterior; Post: posterior; Dors: dorsal; Vent: ventral. 


\begin{tabular}{|c|c|c|c|c|c|c|c|c|c|}
\hline & \multicolumn{3}{|c|}{ Self } & \multicolumn{3}{|c|}{ Other Person } & \multirow{2}{*}{$\begin{array}{c}\text { Self } \\
\text { vs } \\
\text { Other } \\
p\end{array}$} & \multirow{2}{*}{$\begin{array}{c}\text { Object } \\
\text { vs } \\
\text { Body } \\
p\end{array}$} & \multirow{2}{*}{$\begin{array}{c}\text { Interaction } \\
\mathrm{SO} \times \mathrm{OB} \\
p\end{array}$} \\
\hline & Object & Body & All & Object & Body & All & & & \\
\hline$\overline{R T}$ & $637(115)$ & 657 (106) & 647 (110) & $780(183)$ & $838(175)$ & 809 (179) & $<0.001$ & 0.004 & 0.009 \\
\hline $\operatorname{ttp}$ & $263(47)$ & $265(52)$ & 264 (49) & $265(52)$ & $273(50)$ & $269(51)$ & ns & ns & ns \\
\hline$t f p$ & $419(74)$ & $408(69)$ & $413(71)$ & $544(91)$ & $540(91)$ & $542(90)$ & $<0.001$ & ns & ns \\
\hline$d u r$ & $681(105)$ & $673(101)$ & $670(102)$ & 809 (128) & $812(122)$ & $811(124)$ & $<0.001$ & ns & ns \\
\hline maxvel & $1.53(.29)$ & $1.56(.25)$ & $1.54(.27)$ & $1.44(.23)$ & $1.41(.21)$ & $1.42(.22)$ & ns & ns & ns \\
\hline traj & $578(54)$ & $575(47)$ & $576(50)$ & $602(58)$ & 598 (49) & $600(53)$ & ns & ns & ns \\
\hline
\end{tabular}




\begin{tabular}{|c|c|c|c|c|c|c|c|c|c|}
\hline & \multicolumn{3}{|c|}{ Self } & \multicolumn{3}{|c|}{ Manikin } & \multirow{2}{*}{$\begin{array}{c}\text { Self } \\
\text { vs } \\
\text { Manikin } \\
p\end{array}$} & \multirow{2}{*}{$\begin{array}{c}\text { Object } \\
\text { vs } \\
\text { Body } \\
p\end{array}$} & \multirow{2}{*}{$\begin{array}{c}\text { Interaction } \\
\text { SM x OB } \\
p\end{array}$} \\
\hline & Object & Body & All & Object & Body & All & & & \\
\hline$R T$ & 725 (205) & $758(245)$ & $741(224)$ & $1042(352)$ & $1071(391)$ & $1056(368)$ & $<0.001$ & $\mathrm{~ns}$ & $\mathrm{~ns}$ \\
\hline $\operatorname{ttp}$ & $273(44)$ & 277 (46) & $275(44)$ & 294 (57) & 299 (59) & 297 (58) & 0.004 & ns & $\mathrm{ns}$ \\
\hline$t f p$ & $424(85)$ & $442(124)$ & $433(105)$ & $622(145)$ & $632(160)$ & $627(151)$ & $<0.001$ & $\mathrm{~ns}$ & $\mathrm{~ns}$ \\
\hline$d u r$ & 697 (114) & 719 (148) & 708 (131) & $916(173)$ & $931(190)$ & $923(180)$ & $<0.001$ & $\mathrm{~ns}$ & $\mathrm{~ns}$ \\
\hline maxvel & $1.70(.23)$ & $1.66(.19)$ & $1.68(.21)$ & $1.39(.20)$ & $1.38(.20)$ & $1.38(.20)$ & $<0.001$ & ns & ns \\
\hline traj & $616(63)$ & $612(63)$ & $614(62)$ & $665(88)$ & $667(85)$ & $666(88)$ & 0.002 & ns & ns \\
\hline
\end{tabular}




\begin{tabular}{ccccccc}
\hline Anatomic location & Side & BA & T & \multicolumn{3}{c}{ MNI coordinates } \\
& & & & & \\
& & & & & \\
Precuneus & $\mathrm{L}$ & 7 & 4.70 & -12 & -70 & 64 \\
& $\mathrm{R}$ & 7 & 4.47 & 8 & -76 & 60 \\
Superior medial prefrontal & $\mathrm{R}$ & 32 & 4.18 & 2 & 36 & 32 \\
Posterior intraparietal sulcus & $\mathrm{L}$ & 19 & 3.93 & -20 & -64 & 38 \\
Cerebellum & $\mathrm{L}$ & - & 3.81 & -22 & -30 & -28 \\
Middle Occipital * & $\mathrm{L}$ & 19 & 3.42 & -42 & -78 & 4 \\
\hline
\end{tabular}




\begin{tabular}{|c|c|c|c|c|c|c|}
\hline \multirow{2}{*}{$\begin{array}{c}\text { Anatomic location } \\
\text { Parahippocampal/Pons* }\end{array}$} & \multirow{2}{*}{$\begin{array}{l}\text { Side } \\
\text { L }\end{array}$} & \multirow{2}{*}{$\begin{array}{c}\mathrm{BA} \\
-\end{array}$} & \multirow{2}{*}{$\begin{array}{c}\mathrm{T} \\
4.25\end{array}$} & \multicolumn{3}{|c|}{$\begin{array}{c}\text { MNI coordinates } \\
(\mathrm{x}, \mathrm{y}, \mathrm{z})\end{array}$} \\
\hline & & & & -8 & -10 & -24 \\
\hline Middle temporal & $\mathrm{R}$ & 21 & 4.03 & 64 & -8 & -24 \\
\hline Superior frontal & $\mathrm{R}$ & 6 & 4.02 & 26 & 8 & 64 \\
\hline Paracentral lobule & - & 6 & 3.76 & 0 & -12 & 80 \\
\hline Inferior parietal & $\mathrm{R}$ & 7 & 3.72 & 30 & -56 & 52 \\
\hline Inferior frontal & $\mathrm{L}$ & 47 & 3.68 & -32 & 36 & -20 \\
\hline
\end{tabular}




\section{Figure 1}

Click here to download Figure: Figure1_NSY_Cleret_revision.eps

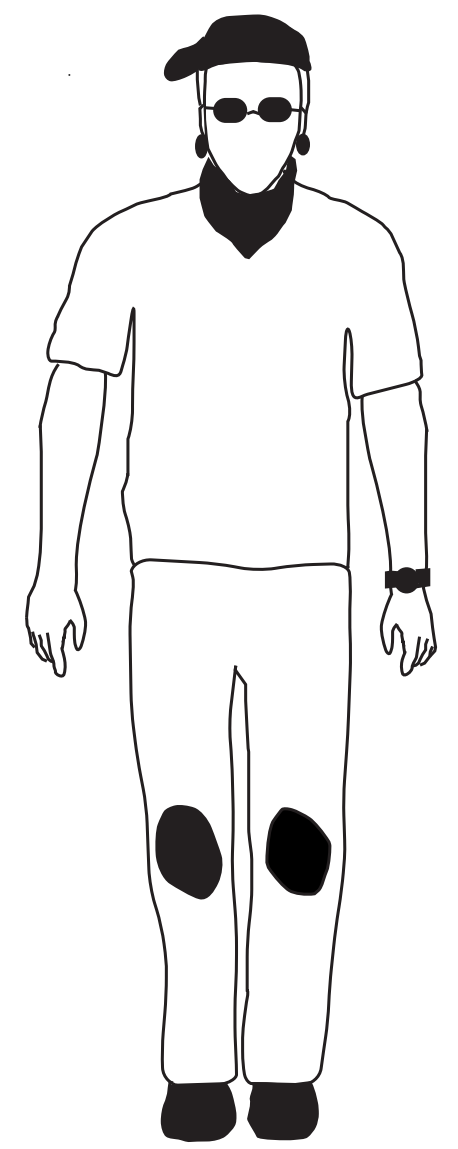

a

Flanking

Addressee

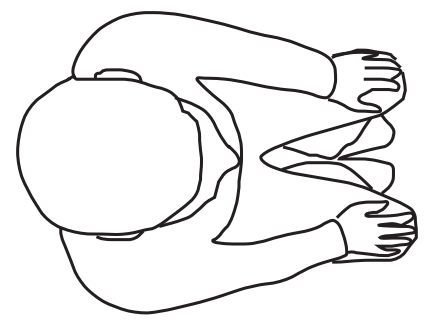

b

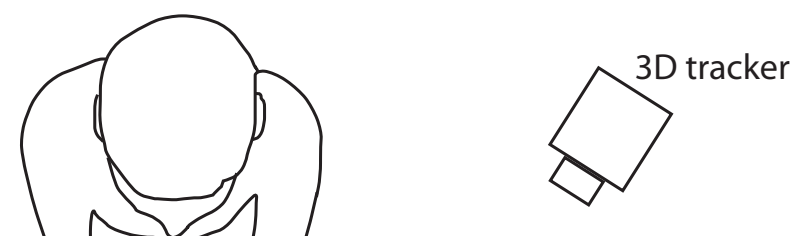

Flanking

Addressee
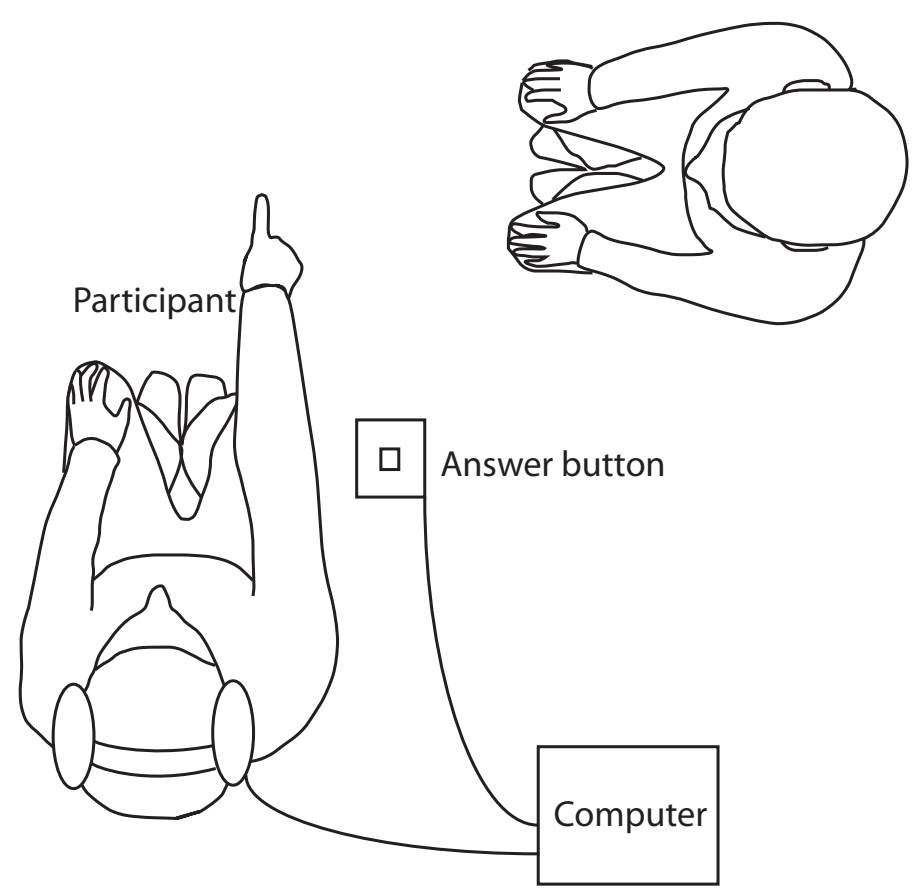

\begin{tabular}{|c|}
\hline $\begin{array}{c}\text { Verbal } \\
\text { Instruction }\end{array}$ \\
\hline $\begin{array}{l}\text { Participant's } \\
\text { Calling the } \\
\text { addressee }\end{array}$ \\
\hline
\end{tabular}

Participant's

Finger on RT button

Movement

parameters

Show to Gilles...

Montrez à Gilles... the nose of Lise

lenezde Lise

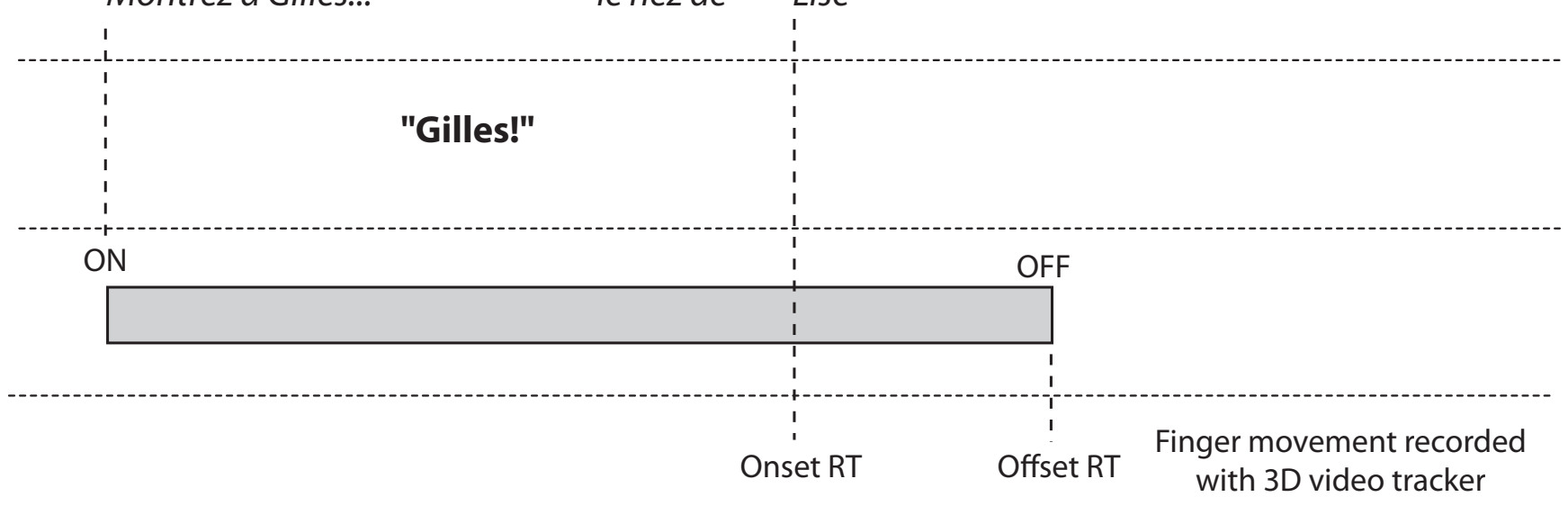

Addressee's

response

"the nose of Lise!" 

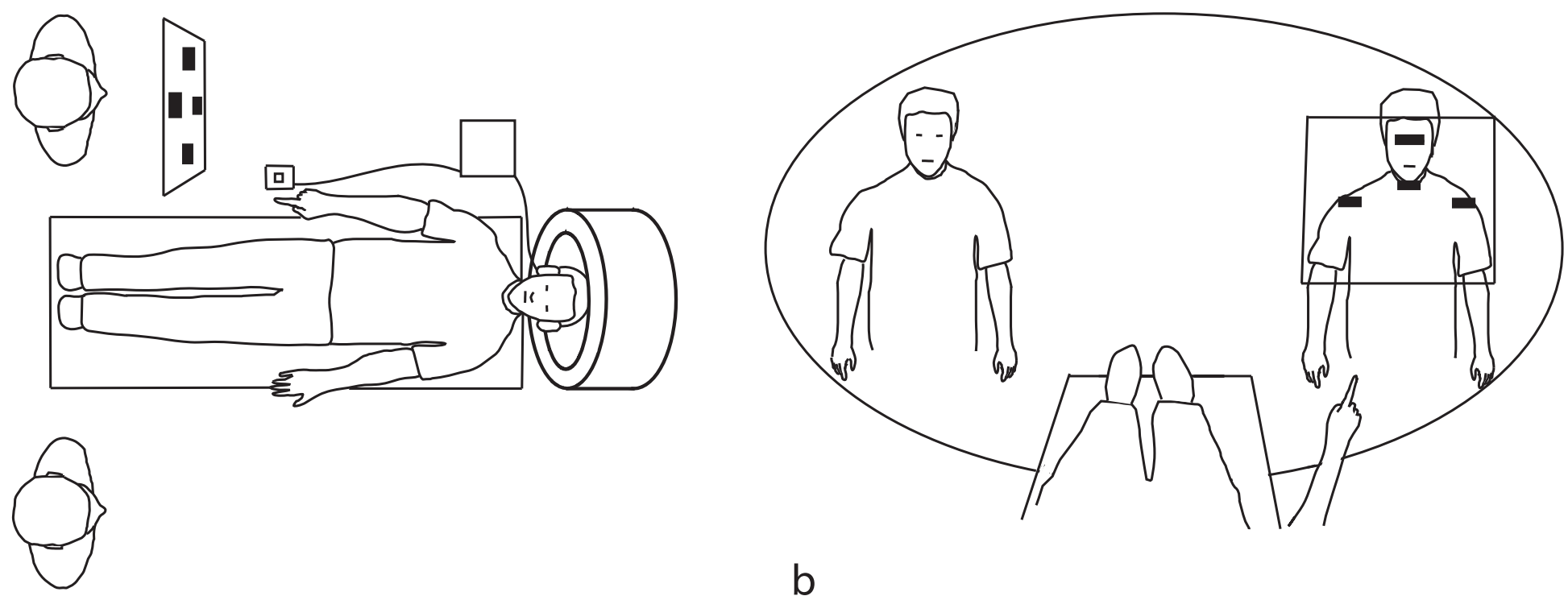

b

\begin{tabular}{|c|}
\hline $\begin{array}{c}\text { Verbal } \\
\text { Instruction }\end{array}$ \\
\hline $\begin{array}{c}\text { Participant's } \\
\text { Calling the } \\
\text { addressee }\end{array}$ \\
\hline $\begin{array}{c}\text { Participant's } \\
\text { Finger on RT } \\
\text { button }\end{array}$ \\
\hline $\begin{array}{c}\text { Reaction } \\
\text { Time }\end{array}$ \\
\hline Addressee's \\
response
\end{tabular}

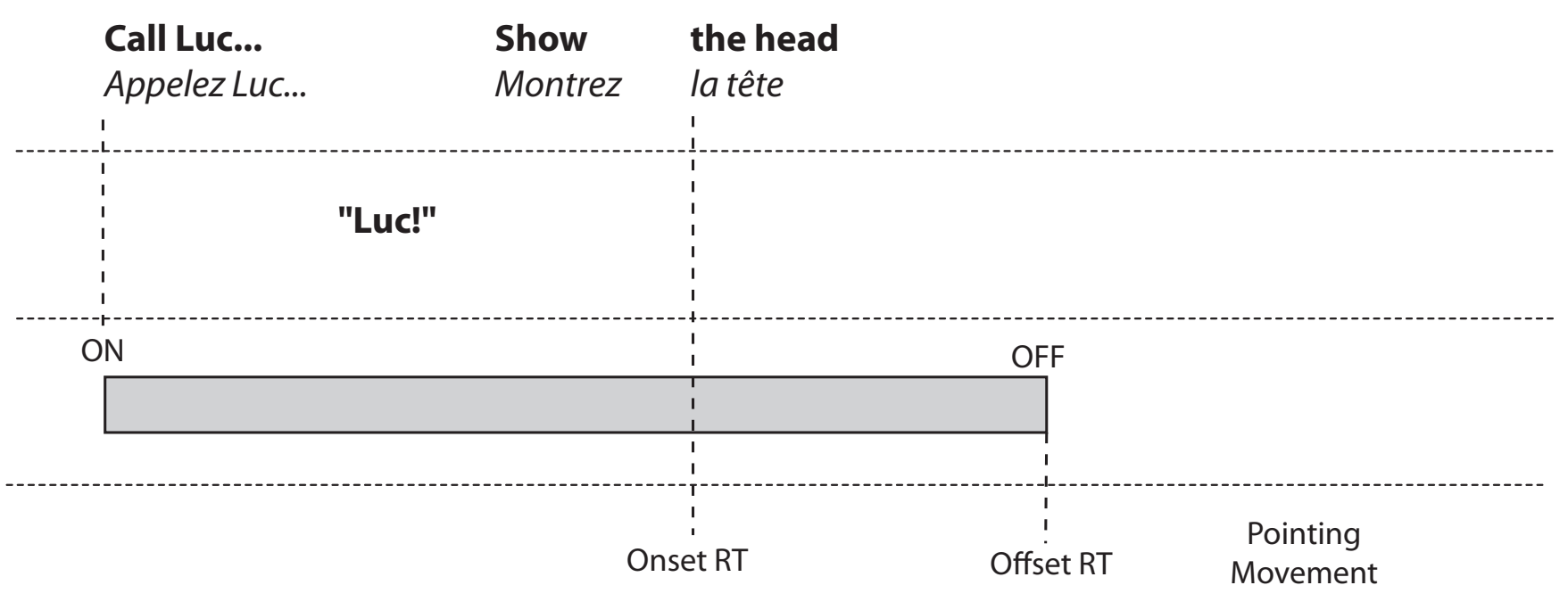


Figure 3

Click here to download Figure: Figure3_NSY_Cleret_revision.eps
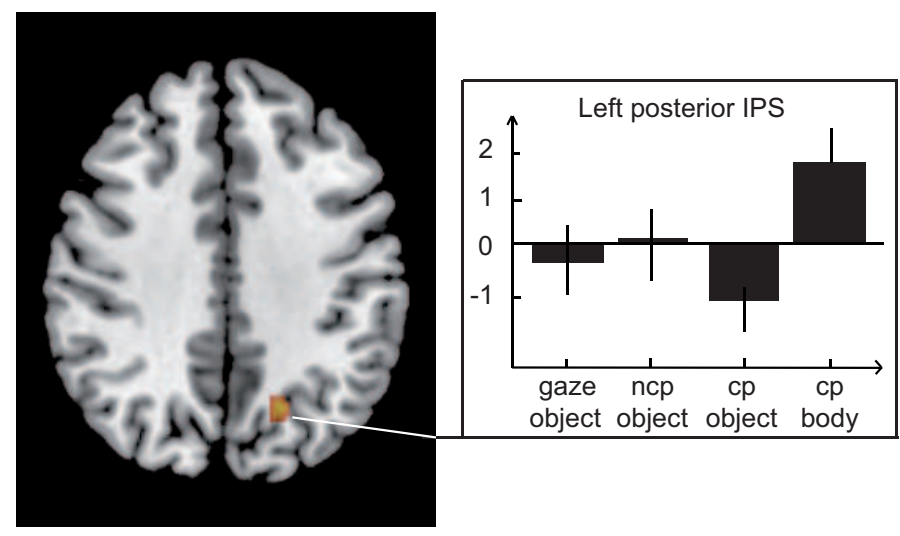

a

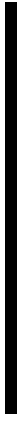

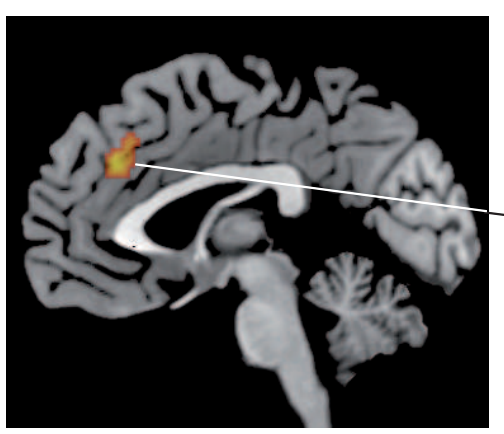

C

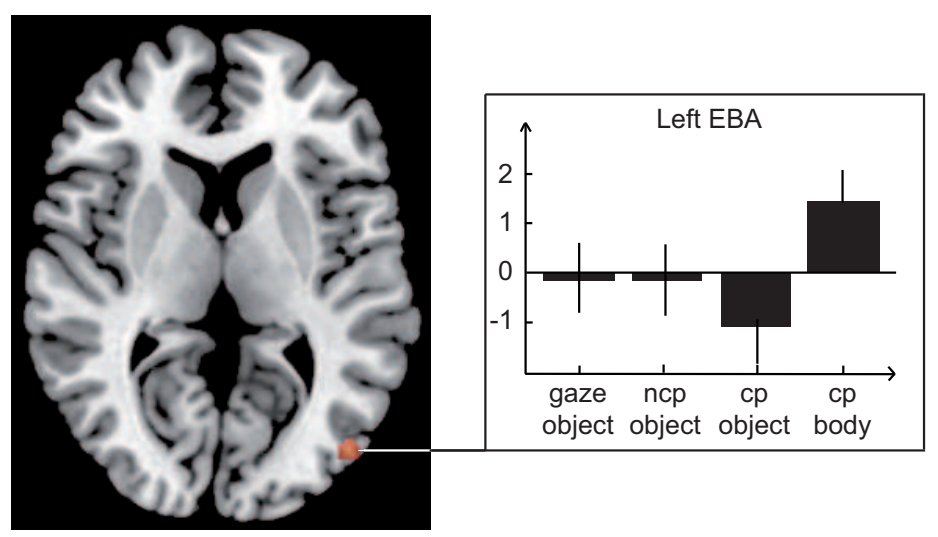

b

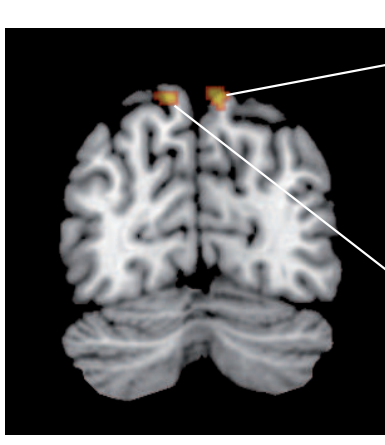

d
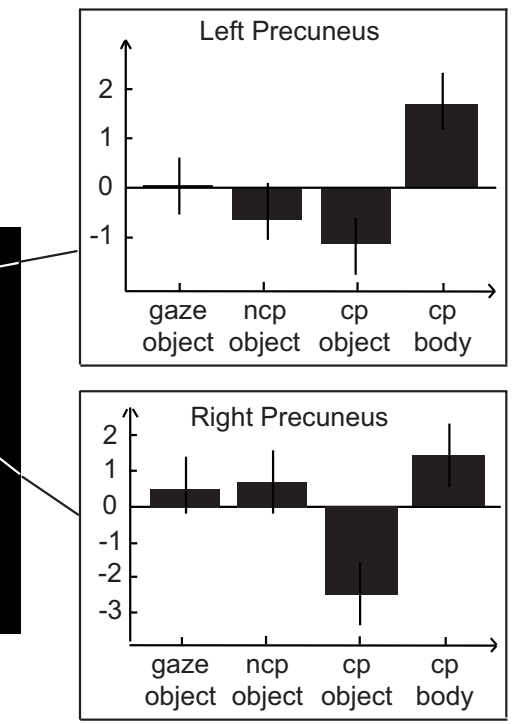
Figure 4

Click here to download Figure: Figure4_NSY_Cleret_revision.eps
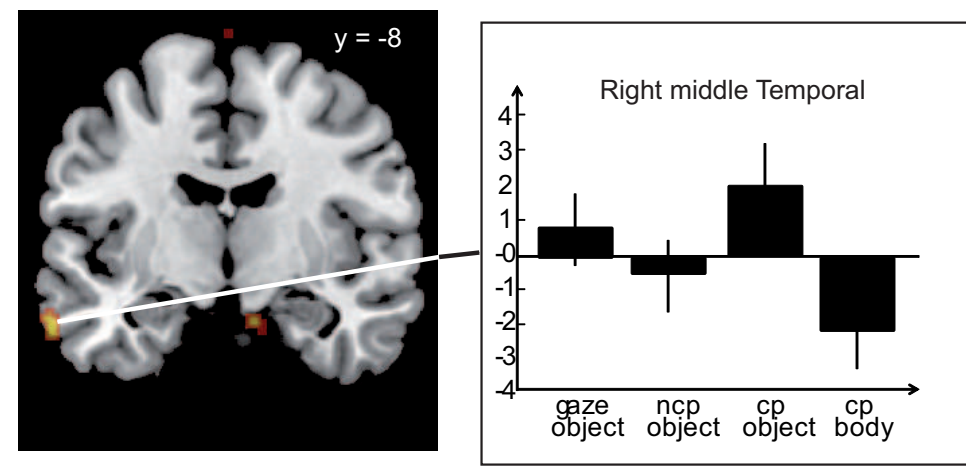

a

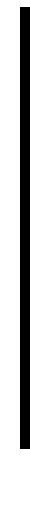

C
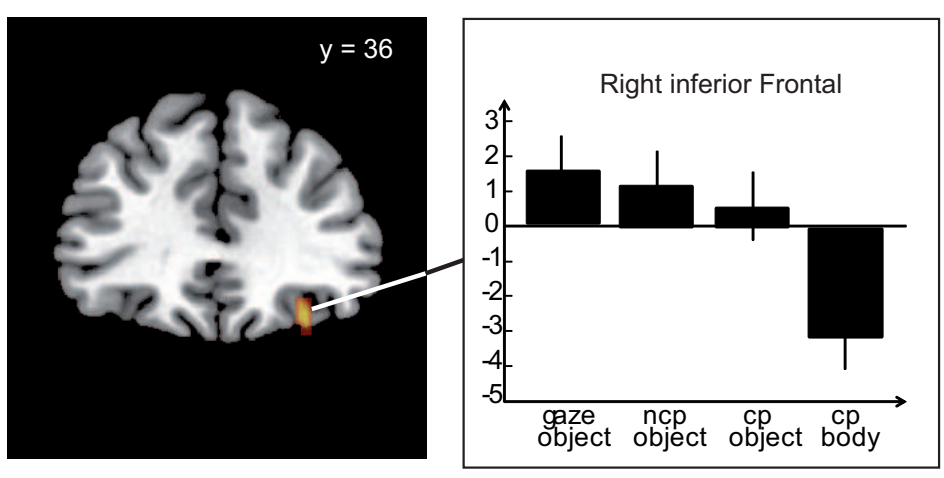

b
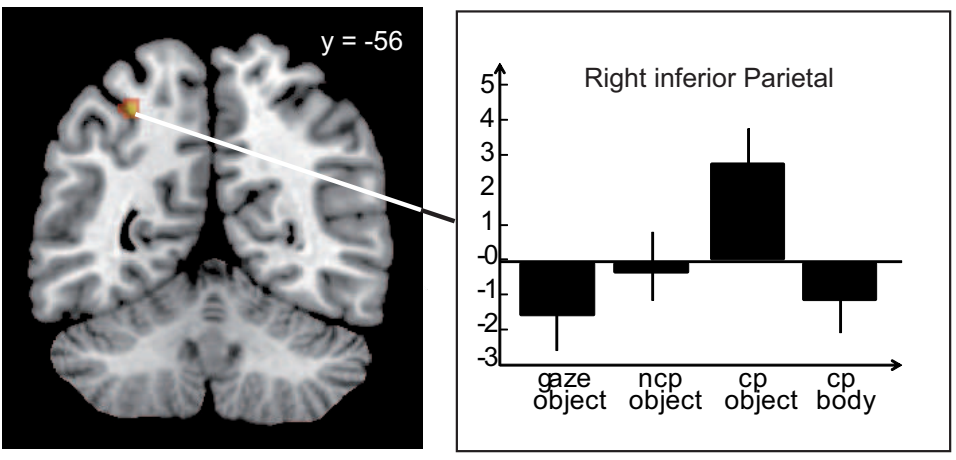


\section{Figure 5}

Click here to download Figure: Figure5_NSY_Cleret.eps

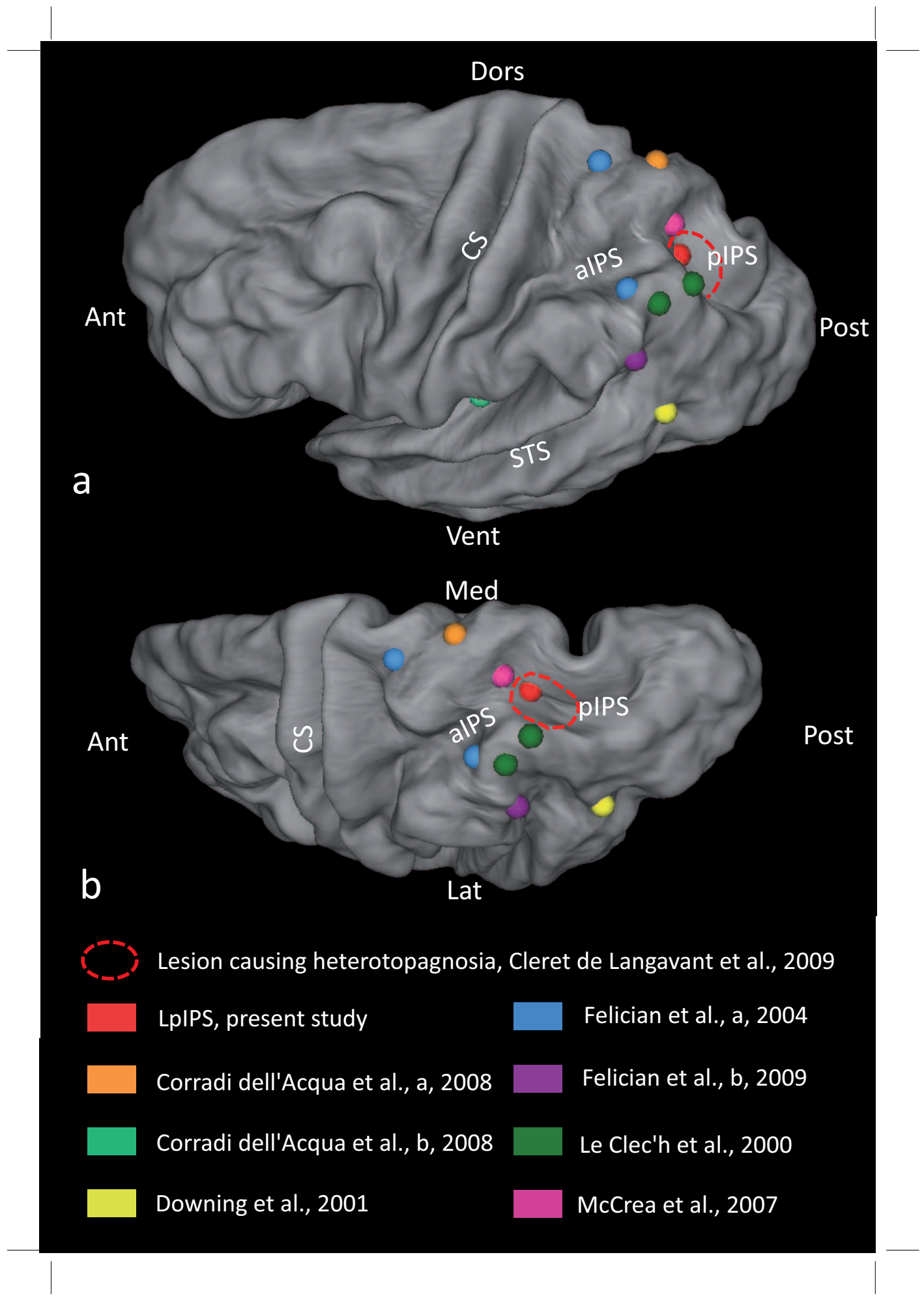

